\title{
MICROSPECTROPHOTOMETRIC DETERMINATION OF THE HAEMO- GLOBIN OXYGEN SATURATION IN HAEMOLYZED ARTERIALIZED CAPILLARY BLOOD
}

\author{
A. H. J. MAAS, L. P. W. A. ZUIJDGEEST AND J. KREUKNIET \\ Departments of Cardiology * and Lung Diseases**, \\ State University Hospital, Utrecht (The Netherlands)
}

(Received May 28th, I963)

\section{SUMMARY}

A description is given of a rapid spectrophotometric micromethod of determining the oxygen saturation in arterialized capillary blood. During sampling, the blood was haemolyzed in a glass capillary with the aid of the haemolytic agent Sterox SE.

Extinctions were measured at $795 \mathrm{~nm}$ and $655 \mathrm{~nm}$ in a cuvette made up of slides $(d=\mathrm{I} \mathrm{mm})$. A single determination is sufficiently exact. Capillary blood from the arterialized earlobe was found to be an adequate substitute for blood from an artery. This method showed good agreement with the haemoreflector method.

\section{INTRODUCTION}

For diagnostic purposes, e.g., heart catheterization, exercise tests and for the correction of the determination of the acid-base balance, rapid and simple determination of the oxygen saturation of the blood is an important requirement.

DRABKIN AND SCHMIDT ${ }^{1}$ developed a spectrophotometric four-wavelength method of determining oxygen saturation, which is exact from a theoretical point of view but technically too complicated for routine use. Many publications have since been presented in which modifications and simplifications of method were described. Reviews on this subject were published by REFSUM AND SveINSSON ${ }^{2}$ and by GEUBEL$\mathrm{LE}^{3}$.

In studies involving repeated determinations of oxygen saturation, it is useful that small quantities of blood should be sufficient for determination, so that the blood loss can be limited (particulary in children), and that capillary blood can be used to avoid arterial puncture.

SiggaARd ANDersen, Jørgensen and Neran ${ }^{4}$ developed a spectrophotometric micromethod for capillary blood, by which the $\mathrm{O}_{2}$ saturation is determined in erythrocytes haemolyzed by freezing and thawing, rather than in haemolyzed whole blood.

In selecting such a method, it seemed simpler to haemolyze whole blood directly while obtaining it. To ensure a more exact result, we used the spectrophotometric isosbestic point method with wavelengths $795 \mathrm{~nm}$ and $655 \mathrm{~nm}$ (GEUBELLE ${ }^{3}$; GoRDY AND DRABKIn ${ }^{5}$ ). A special cuvette with a $\mathrm{I}-\mathrm{mm}$ path length was designed for this

* Prof. R. L. J. van Ruyven.

** Prof. Dr. H. Deenstra. 
purpose. To verify the reliability of the method, we compared the oxygen saturation of arterial blood with that of capillary blood. In addition, we compared the method with the haemoreflector method of ZIJLSTRA ${ }^{6}$ employed at our clinic.

\section{MATERIALS AND METHOD}

\section{Principle}

Analogous to the procedure of GEUBeLle ${ }^{3}$ and Gordy ANd Drabkin ${ }^{5}$, we determined the oxygen saturation of blood haemolysed with the detergent Sterox SE, by the isosbestic point method of NAHAS ${ }^{7}$ from the extinction $(D)$ measured at an isosbestic wavelength $(795 \mathrm{~nm})$ and that at a wavelength at which the light absorption of reduced haemoglobin far exceeds that of oxygenated haemoglobin $(655 \mathrm{~nm})$. For the oxygen saturation of the blood $(S)$ we then obtain the equation:

$$
S=a \frac{D_{555}}{D_{795}}+b,
$$

in which $a$ and $b$ are constants.

\section{Reagents and apparatus}

Trafuril paste (Ciba) and plasticine. A buffered heparin Sterox SE solution, $\mathrm{pH} \approx 7.4(\mathrm{I} \mathrm{ml} \mathrm{heparin} \mathrm{solution} 5000 \mathrm{I}$.U. $/ \mathrm{ml} ; 20 \mathrm{ml}$ Sterox SE (Hartman Leddon Co., Philadelphia, Pa., USA); $0.949 \mathrm{~g} \mathrm{Na}{ }_{2} \mathrm{HPO}_{4} \cdot 2 \mathrm{H}_{2} \mathrm{O}$ and $0.182 \mathrm{~g} \mathrm{KH}_{2} \mathrm{PO}_{4}$, with distilled water up to $100 \mathrm{ml})$.

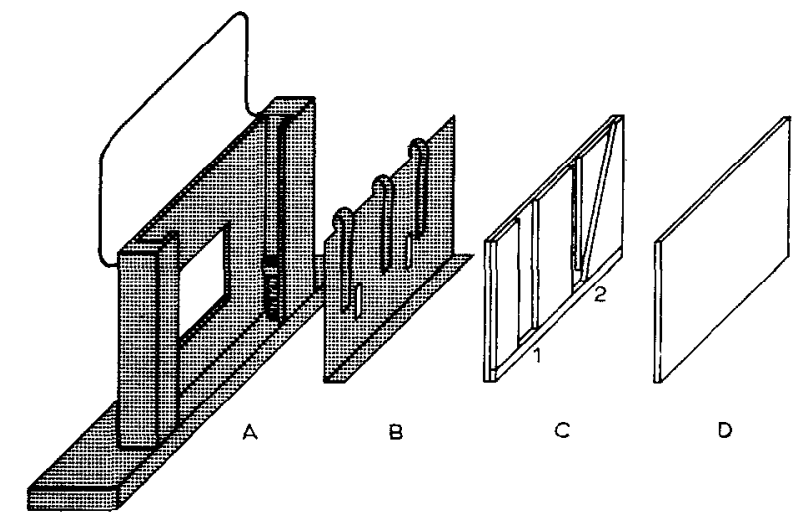

Fig. I. Microcuvette with holder for Beckmann model DU spectrophotometer.

Clean glass capillary tubes (length $\approx 12 \mathrm{~cm}$, capacity $\approx 70 \mu \mathrm{l}$ ), with fitting fragments of steel wire (length $\mathrm{r} .5 \mathrm{~cm}$ ) and a magnet (Radiometer, Copenhagen).

A Beckman model DU spectrophotometer.

A microcuvelte*, palh length $1 \mathrm{~mm}$, made up of three flat slides (each $1 \mathrm{~mm}$ thick) (Fig. I).

The parts of one slide are glued onto the other in such a way as to form two

* Special microcuvettes $(3 \times$ I $\times 25 \mathrm{~mm}$, No. I05-OS), which can be used for each spectrophotometer are available from Hellma (Freibourg, Germany). 
lumina, viz. $\mathrm{C}_{1}$ (chamber for reference fluid, water) measuring $5 \times \mathrm{r} \times 22 \mathrm{~mm}$, and $\mathrm{C}_{2}$ (filling canal $\varnothing \mathrm{I} \mathrm{mm}$ and chamber for measuring fluid), of $2 \times \mathrm{I} \times 22 \mathrm{~mm}$ size.

For closure we used slide D which, with the aid of copper clamp B, was firmly pressed onto $\mathrm{C}$, the contact surfaces of which had been greased with a thin layer of silicone grease. The cuvette fits in holder A, which for the Beckman spectrophotometer was designed by Siggaard Andersen (Dansk Laboratorie Udstyr, Copenhagen).

Tonometer equipment according to Von LauE ${ }^{8}$ (Eschweiler, Kiel).

\section{Procedure}

Blood sampling with haemolysis. The inside wall of two glass capillaries was moistened with Sterox SE buffer solution by repeatedly filling and emptying with the aid of a rubber tube. The earlobe was then cleaned with alcohol, and hyperaemia was produced by rubbing with Trafuril paste. The paste was allowed to exert its influence for at least Io min., after which the remnants were removed with alcohol. After puncture with a snapper and wiping off the first drop of blood, a capillary was held into the next drop and gently pressed against the earlobe. The capillary was filled by slight suction with the rubber tube. This tube was then removed, and the capillary was sealed on this end with plasticine. On the other end, a small nail was inserted into the capillary, which was then also sealed with plasticine. With the aid of the magnet, the nail was carefully moved up and down until haemolysis was complete.

Arterial blood from the brachial artery was sampled as described by MAAS AND VAN HEIJST ${ }^{9}$. Heparinized venous blood was used in making the calibration line.

Measurement of the oxygen saturation. The Beckman model DU spectrophotometer was adjusted on the red photo-tube, slit 0.03 and wavelengths $6.55 \mathrm{~nm}$ and $795 \mathrm{~nm}$, respectively. With a glass knife, the two plasticine seals were cut off the capillary, and the nail was removed with the aid of the magnet. The measuring chamber of the cuvette $\left(\mathrm{C}_{2}\right)$ was then filled with the haemolysate by placing the capillary on the filling canal in vertical position, allowing it to empty. Chamber $\mathrm{C}_{1}$ was filled with distilled water. At wavelength $655 \mathrm{~nm}$ and $795 \mathrm{~nm}$, respectively, the extinctions relative to distilled water were determined. After completion of measurements the cuvette was washed out with distilled water and air-dried by suction.

Calculation. For the determination of the constants $a$ and $b$ (eqn. (I)), $2 \mathrm{ml}$ heparinized venous blood from $I_{5}$ different fasting patients was equilibrated at $38^{\circ}$ $(\mathrm{I} \mathrm{h})$ with water vapour-saturated gas mixtures of composition $5 \% \mathrm{CO}_{2}, 95 \% \mathrm{O}_{2}$, and $5 \% \mathrm{CO}_{2}, 95 \% \mathrm{~N}_{2}$ (oxygen-free). After this, $0.2 \mathrm{ml}$ Sterox buffer solution (air-free) was added. For the extinction ratio $\frac{\left(D_{655}\right)}{\left(D_{795}\right)_{\mathrm{Hb}}}$, we found as a mean of I5 determinations 3.898 (S.D. =o.oI6); for the extinction ratio $\frac{\left(D_{655}\right)}{\left(D_{795}\right)_{\mathrm{HbO}}}$ we found 0.437 (S.D. $\left.=0.0 \mathrm{Io}\right)$.

From this we calculated the calibration line for a blood sample:

$$
S=-28.89 \frac{\left(D_{655}\right)}{\left(D_{795}\right)}+\operatorname{Ir} 2.6 \mathrm{I}
$$


TABLE I

OXYGEN SATURATION VALUES OF BLOOD SIMULTANEOUSLY OBTAINED FROM THE BRACHIAL ARTERY AND EARLOBE, AS MEASURED BY THE MICROMETHOD DESCRIBED AND BY THE HAEMOREFLECTOR METHOD

\begin{tabular}{|c|c|c|c|c|c|c|c|c|}
\hline \multicolumn{6}{|c|}{ Percentual oxygen saturation } & \multicolumn{3}{|c|}{ Difference in percentual oxygen saturation } \\
\hline \multirow{3}{*}{ No. } & \multirow{2}{*}{\multicolumn{3}{|c|}{$\begin{array}{c}\text { Blood from } \\
\text { the } \\
\text { earlobe } \\
\text { Micromethod }\end{array}$}} & \multicolumn{2}{|c|}{$\begin{array}{c}\text { Blood from } \\
\text { the brachial } \\
\text { artery }\end{array}$} & \multirow{3}{*}{$\begin{array}{c}\text { of the duplicate } \\
\text { determination } \\
\text { of blood from } \\
\text { the earlobe } \\
a-b\end{array}$} & \multirow{3}{*}{$\begin{array}{l}\text { of blood from the } \\
\text { earlobe - brachial } \\
\text { artery } \\
\text { Micromethod } \\
\text { (1)-(2) }\end{array}$} & \multirow{3}{*}{$\begin{array}{c}\begin{array}{c}\text { of blood from } \\
\text { the brachial } \\
\text { artery }\end{array} \\
\text { Micromethod - Haemo } \\
(2)-(3)\end{array}$} \\
\hline & & & & \multirow{2}{*}{$\begin{array}{l}\text { Micro- } \\
\text { method } \\
\text { (2) }\end{array}$} & \multirow{2}{*}{$\begin{array}{l}\text { Haemo- } \\
\text { reflector } \\
\text { (3) }\end{array}$} & & & \\
\hline & $a$ & $b$ & $\begin{array}{c}\text { (I) } \\
\text { mean }\end{array}$ & & & & & \\
\hline I & 96.5 & 96.6 & 96.5 & 9.64 & 97.5 & -0.1 & +0.1 & $-\mathrm{I} . \mathrm{I}$ \\
\hline 2 & 83.7 & 83.5 & 83.6 & 82.8 & 83.0 & +0.2 & +0.8 & -0.2 \\
\hline 3 & 98.5 & 98.5 & 98.5 & 98.6 & 98.0 & 0.0 & $-\mathrm{O} . \mathrm{I}$ & +0.6 \\
\hline 4 & 95.9 & 96.3 & $96 . \mathrm{I}$ & 96.2 & 97.0 & -0.4 & - o.I & -0.8 \\
\hline 5 & 92.8 & 92.9 & 92.8 & 92.9 & 94.5 & $-0 . I$ & $-0 . \mathrm{I}$ & $-\mathrm{I} .6$ \\
\hline 6 & 93.0 & 93.0 & 93.0 & 91.8 & 94.0 & 0.0 & $+\mathrm{x} .2$ & -2.2 \\
\hline 7 & 96.8 & 96.8 & 96.8 & 97.1 & 97.5 & 0.0 & -0.3 & -0.4 \\
\hline 8 & 93.1 & 93.1 & 93.I & 94.4 & 95.5 & 0.0 & $-\mathbf{I} \cdot 3$ & - I.I \\
\hline 9 & 96.2 & 96.2 & 96.2 & 96.3 & 95.5 & 0.0 & $-0 . I$ & +0.8 \\
\hline ro & 94.5 & 94.6 & 94.6 & 94.6 & $94-5$ & $-\mathrm{O} . \mathrm{I}$ & 0.0 & $+0 . x$ \\
\hline I I & 98.3 & - & 98.3 & 99.2 & 98.5 & - & -0.9 & +0.7 \\
\hline I2 & 84.7 & 一 & 84.7 & $83 \cdot 7$ & 81.5 & - & -1.0 & +2.2 \\
\hline I3 & 94.7 & 94.5 & 94.6 & 95.9 & 95.5 & +0.2 & -1.3 & +0.4 \\
\hline I 4 & 94.3 & - & $94 \cdot 3$ & 94.3 & 93.5 & - & 0.0 & +0.8 \\
\hline I 5 & 96.7 & 96.8 & 96.8 & 96.3 & 97.5 & $-O . I$ & +0.5 & $-\mathrm{I} .2$ \\
\hline I6 & 92.8 & 92.4 & 92.6 & 93.9 & 95.5 & +0.4 & -1.3 & $-\mathrm{I} .6$ \\
\hline I7 & $95 \cdot 7$ & 95.8 & 95.8 & 94.8 & 97.0 & $-\mathrm{O} . \mathrm{I}$ & $+\mathbf{I} . \mathbf{O}$ & -2.2 \\
\hline 18 & 97.9 & 98.0 & 98.0 & 96.6 & 95.0 & $-0 . I$ & $+\mathbf{r} .4$ & $+\mathrm{r} .6$ \\
\hline 19 & 95.9 & 95.7 & 95.8 & 96.9 & 96.2 & +0.2 & $-\mathrm{I} . \mathrm{I}$ & +0.7 \\
\hline \multirow[t]{2}{*}{20} & 94.9 & 94.9 & 94.9 & 94.2 & 96.5 & 0.0 & +0.7 & -2.3 \\
\hline & & & & & & $\begin{array}{c}\bar{X}=0.0 \\
\text { S.D. }=0.16\end{array}$ & $\begin{array}{rr}\bar{X}= & -0 . I \\
S . D . & =0.8\end{array}$ & $\begin{aligned} \bar{X} & =-\mathrm{c} .34 \\
S . D . & =\mathrm{I} .3 \mathrm{I}\end{aligned}$ \\
\hline
\end{tabular}

\section{RESULTS}

Blood was taken simultaneously from the earlobe and the brachial artery of 20 patients, and the oxygen saturation of both samples was spectrophotometrically determined. In addition, blood from the brachial artery was used in comparative measurements with the haemoreflector. The results are presented in Table I.

\section{DISCUSSION}

Our method is a modification of the method of GEUBELLE ${ }^{3}$ and GoRDY AND DRABKIN ${ }^{5}$, who haemolysed whole blood with saponin, and measured at wavelengths $650 \mathrm{~nm}$ and $805 \mathrm{~nm}$. Our experience has shown that it is difficult to ensure complete haemolysis of blood in capillaries with saponin.

DEIBLER ${ }^{10}$, therefore, used Triton-X as haemolytic agent in his oxygen-saturation determinations. We have examined the action of this agent and compared it with that of the detergent Sterox SE. The ultimate results were identical, but Sterox SE haemolyzed more rapidly and more effectively than Triton-X. The Sterox SE buffer solution used in our study is clear and stable and need not be freshly prepared every day. In order to inhibit displacement of the oxygen dissociation curve as much as possible, we chose a phosphate buffer of $\mathrm{pH} \approx 7.4$ (normal blood $\mathrm{pH}$ value). The great advantage of this haemolysis method over the method of freezing and thawing lies 
in the fact that haemolysis is effected immediately during blood sampling, which makes this determination a rapid routine analysis.

GeUbelle $^{3}$ and Gordy and Drabkin ${ }^{5}$ used wavelengths $805 \mathrm{~nm}$ (isosbestic point) and $650 \mathrm{~nm}$. From $\mathrm{I} 2$ absorption spectrum curves of oxygenated and reduced blood we established the value $797 \pm 2 \mathrm{~nm}$ for the isosbestic point. Since the monochromator in routine is better adjusted to $795 \mathrm{~nm}$, we chose this value. This point, however, is not critical because the two absorption curves intersect at a narrow angle at this point. The fact that we found a value lower than $805 \mathrm{~nm}$ must be ascribed, we think, to the method of reduction and the $\mathrm{pH}$ value of the haemolysate. The above mentioned authors reduced with $\mathrm{Na}_{2} \mathrm{~S}_{2} \mathrm{O}_{4}$, and worked at pH 8-9. Wavelength $655 \mathrm{~nm}$ instead of $650 \mathrm{~nm}$ was chosen after FEINBERG ${ }^{11}$, because this value is nearer the isosbestic point of haemoglobin $(\mathrm{Hb})$ and methaemoglobin $(\mathrm{MHb})(657.5 \mathrm{~nm})$. Adjustment to wavelength $655 \mathrm{~nm}$ with the monochromator, however, is critical and must be done exactly, because the absorption curves of oxygenated and of reduced haemoglobin are steep at this wavelength. The reliability of the method was studied by comparing the oxygen saturation of arterialized blood from the earlobe with that of blood simultaneously obtained from the brachial artery. We found a difference of $0 . \mathbf{1} \%$, which is not significant ( $c f$. Table I). The excellent efficiency of Trafuril makes it possible to obtain blood equivalent to arterial blood.

Comparative measurements of arterial blood with the haemoreflector (reflection method) routinely used at our clinic, showed no essential difference (0.3\%).

By this two-wavelength method an apparent oxygen saturation is determined, because the extinctions of $\mathrm{MHb}$ and $\mathrm{HbCO}$ are also measured. Normally, the concentration of both components in blood is about $0.5 \%$, and consequently this produces a constant error. A detailed discussion of this subject has been presented by GoRDY AND DRABKIN ${ }^{5}$. Special attention must be given to smokers among the test subjects $\left(\right.$ REFSUM $\left.^{13}\right)$.

\section{ACKNOWLEDLGEMENT}

The authors gratefully acknowledge helpful discussions with Dr. E. B. M. DE Jons (St. F.lisahethriekenhuis, Tilburg) and Dr. B. F. VIsser (Department of Lung Diseases).

The technical assistance of Miss G. A. M. Zandwijk and Miss J. M. Groennuujsen is greatly appreciated.

\section{REFERENCES}

1 D. L. Drabkin and C. F. Schmidt, J. Biol. Chem, i 57 (I945) 69.

- H. E. Rersum and S. L. Svernsson, Scand. J. Clin. Lab. Invesl., 8 (I956) 67.

3 F. Geubelle, Clin. Chim. Acta, I (1956) 228.

4 O. Siggatrd Andersen, K. Jørgensen and N. Neran, Scand. J. Clin. Lab. Invest., I4 (Ig62) 320 .

5 E. GORdY AND D. L. DRABkin, J. Biol. Ghem, 227 (I957) 285.

- W. G. ZiJlstra, Fundamentals and Applications of Clinical Oxymetry, Van Gorcum and Co., Assen, The Netherlands, I95 $\mathrm{I}$.

7 G. G. NAHAS, Science, II 3 (I95I) 723 .

8 D. Von Lauti, Pflïgers Arch. Ges. Physiol., 254 (I95I) I 42.

9 A. H. J. Maas and A. N. P. van Heijst, Clin. Chim. Acta, 6 (I96I) $3 \mathrm{I}$.

10 G. E. Deibler, M. S. Holmes, Ph. L. Campbell and J. Gans, J. Appl. Physiol., I4 (r959) I 33

11 H. Feinderg and Sister Mary Alma, J. Lab. Clin. Med., 55 (I960) $7^{84}$.

12 P. Astrup, Ciba Foundation Reseavch Forum, r958.

13 H. E. Refsum, Scand. J. Clin. Lab. Invest., 9 (1957) I9o. 